\title{
Tourism Breeding Environment: Forms and Levels of Collaboration in the Tourism Sector
}

\author{
Salvatore Ammirato and Alberto Michele Felicetti \\ Department of Mechanical Energy and Management Engineering, University of Calabria \\ via P. Bucci, 42lC, 87036 Rende (CS), Italy \\ \{salvatore.ammirato, alberto.felicetti\}@unical.it
}

\begin{abstract}
Tourism, one of the largest industries in the world, has been subject to strong innovation in the last years. Main changes are due to the availability of new Information and Communication Technologies, which directly connect tourists among them and with service providers, and to the always more personalized supply of tourism experience. Such evolution may represent a driver of development for local communities if they are able to reorganize the territorial tourism offer around different pattern of collaboration. In this paper we propose an organizational model for a Tourism Breeding Environment, TBE, whose members are tourism operators of a regional area with tourist vocation. After discussing about which forms of collaborative networked organizations can rise from the TBE, we present a classification of the different levels of collaboration emerging in those forms.
\end{abstract}

Keywords: Tourism Breeding Environment, Collaborative Networked Organizations, Tourism Extended Enterprise, Tourism Virtual Organization.

\section{Introduction}

Tourism made a significant contribution to the economies of many nations around the world because of its ability to create income, taxes, and employment [1]. T provides a strong impact on the global economic development, employing more than 210 million people worldwide (7.6\% of global employment) and generating an estimated US\$ 5,474 billion of economic activity (9.4\% of global GDP) [2]. Impressive changes in the ICTs and the Internet caused an extensive transformation of the industry. Demand and supply of ICT have innovated considerably Tourism Sector in operational workflows, management and marketing of tourism packages and new paradigms in tourism experiences [3]. ICTs provide significant opportunities for internal business process re-engineering and e-business, at the company level, while, at the industry level, ICTs allow communication and information exchange with partners, integration of information flows from a wide spectrum of suppliers, and new patterns for the customer care [4].

Changes are evident from the industry side. The Internet is changing the industry structure by altering barriers to entry, revolutionizing distribution channels, facilitating price transparency and competition, as well as enhancing production efficiency [5]. As tourism companies become a part of the global economy, local collaborative actions that 
generate externalities for the companies increased in importance. Engaging in new forms of collaboration and maintaining relationships within business networks have become a natural way for organizations to meet performance requirements in competitive markets [6][7]. Since nineties, several case studies and models highlight the increasing importance of tourism partnerships, assessing new organizational forms and identifying key factors in successfully initiating and sustaining tourism development [8][9]. Many case studies in literature agree that a high integration level among partners results in terms of internal efficiency and resource saving of partners in collaboration. Furthermore, problems are better understood when analysed from different perspectives, thus a collection of differently skilled partners can, in principle, go beyond individual knowledge and reach new solutions for the whole business network's questions [10][11][12][13].

From tourist side, the breakdown of geographical and cultural barriers is a result of international cooperation/exchange agreements and fast advances in transportation, communication and electronic communication. New and cheap means of transport, reductions in custom duties and on limitations to cross-countries tourism, allow people easy consuming of tourism products. E-commerce developments enable tourist to interact directly with tourism service providers, allowing travelers to retrieve reliable and accurate information in a fraction of the time, cost and inconvenience required by conventional methods, often disintermediating traditional players of tourism market such as travel agencies and tour operators [14]. Furthermore, new forms of tourism experiences are emerging related to the rediscovery of rural places as a way to gain wellbeing and relaxed life by enjoying the benefits of relocalisation [15]. From these changes, main consequences for tourists are:

- from an operational viewpoint, the ever more diffused self-creations of tourism packages, often comprising online reservations and payments [16].

- From a decisional point of view, the increasing request for personalized forms of tourism experience sometimes based on the rediscovery of cultural heritage, folklore, traditions, as well as on the direct contact with the nature [17] [18] .

In many regions with tourism vocation, local entrepreneurs have started organizing themselves in tourism networks in order to create aggregate tourism offers able to compete with big players. New business models have developed with the aim to reach competitive advantages, to improve revenue streams, to return in taking an active role in the tourism system, and to develop new consumer market niches [19]. Such models of collaborative networks in the tourism sector are characterized by a direct connection among local service providers and tourists with these explicit ethical and political goals: re-vitalisation of territory identity and local community relations to local natural, cultural and historical heritage, linking with sustainable agriculture and handicraft, economically viable and socially responsible practices [20].

In this paper we propose an organizational model of breeding environment for the tourism sector where regional tourism operators can operate in order to timely exploit opportunities coming from the tourism industry evolution while gaining sustainable development for the whole regional area. The paper is organized as follows. After summarizing latest trends in tourism market in section 2, a characterization of the organizational forms of collaborative networked organizations proper of the tourism sector is proposed in section 3. Section 4 discusses the possible levels of collaboration that can be observed during collaboration while section 5 contains conclusions. 


\section{Tourism Breeding Environment and Forms of Collaboration}

In a territory with a touristic vocation, live and operate autonomous entities whose business is related to the sector. While these entities can be heterogeneous in terms of their operating environment, culture and goals, they all aim to achieve the common goal of local tourism development and to increase the general competitiveness respect to other geographical areas and global competition. These entities constitute the reference universe of this study and we define them as Regional tourism operators.

The regional tourism operators can be grouped into the following categories:

- Hospitality Services Enterprises: companies that offer overnight accommodation (e.g. hotels, B\&B) and meal provision (e.g. restaurant).

- Transportation Services providers: public and private companies that provide services of people transportation (i.e. buses, taxies, airplanes, trains, etc).

- Event Management Services: public and private companies dealing with the organization of events (e.g.: conferences, concerts, exhibitions, sport events).

- Tourism complementary goods and services providers: e.g. local shops, museums, excursion services, sport \& leisure facilities, handicrafts.

- Destination Marketing Organizations: that promote incoming tourism and Tour operators that purchase/book services to combine and resell them.

When some of the regional tourism operators decide to reinforce collaboration, they can set stable agreements in the forms of Touristic Associations or Touristic Districts, adhering to a base long term cooperation agreement, and adopting common operating principles and infrastructures. Each agreement is characterized by an own organizational form in terms of structure of membership, activities, definition of roles of the participants, governance principles and rules [21]. We name each of such agreements as a Tourism Breeding Environment (TBE) [22] i.e. a Breeding Environment in tourism sector whose members share values, culture and infrastructures and have the potential and the will to cooperate in order to pursue the general long-term objectives of territory development and competitiveness [23]. In a $\mathrm{TBE}$, each member competes with the others and with players outside the TBE in searching for new business opportunities in the global market. When a business opportunity is identified, a subset of the TBE members can be rapidly selected to become part of a short term Collaborative Networked Organizations, CNOs, oriented to catch the opportunity. Two kinds of short term CNOs are most evident in a TBE:

- Tourism Extended Enterprise (TEE): it refers to a tourism operator that "extends" its business boundaries by involving all or some of its suppliers in the product packaging and delivery in order to offer customers possibilities to a more complete tourism experience. For example, a TEE can be formed by a hotel that stipulates commercial agreements with restaurants, lidos, amusement parks, cruise ship companies. Tourist perceives the overall TEE offer as a whole and, typically, purchase it directly at the hotel (web)site.

- Tourism Virtual Organization (TVO): It represents a temporary alliance of private and public organizations that come together to share skills or core competencies and resources in order to better respond to business opportunities, and whose collaboration is supported by computer networks. A TVO is 
established in a short time to respond to a competitive market opportunity; it has a short life cycle dissolving when the short-term purpose of the TVO is accomplished [23]. ICT advances enable tourists in customizing services on the basis of their own specific tastes [24]. Availability of systems for tourism packaging enable tourist to (self) compose a personalized tourism product choosing a subset of services provided by TBE members (an example of tourism package can be: 2 nights in the hotel A, 1 night in the hotel $\mathrm{B}, 2$ meals in the restaurants $\mathrm{C}, 1$ ticket for a football match, etc.). The set of all services in its personalized package is, usually, supplied by more than one service provider; tourist, while purchasing the package, is indirectly triggering a TVO responsible to deliver the personalized tourism package.

\section{Levels of Collaboration in a Tourism Breeding Environment}

Tourism operators may interact in different way in a TBE. Four coalition's types can be recognized within a TBE, each of them represents a different level of integration among considered groups of actors: networking, coordination, cooperation, collaboration [25]. According to [25], "as we move along the continuum from networking to collaboration, we increase the amounts of common goal-oriented risk taking, commitment, and resources that participants must invest into the joint endeavor". In what follows we propose the four levels highlighting, for each of them, characteristics of interactions and types of technologies best suited to supporting collaboration among partners.

Level 1 - Networking. It involves communication and information exchange for mutual benefit of TBE. Each TBE actor involved in the relationship can benefit from the information shared but there is not necessarily a common goal influencing individual contributions as well as there is no common generation of value. At this level, it's not possible to highlight the presence of CNOs within the TBE. A TBE offer to each tourism operator a way to grasp opportunities that current demand of tourist flows is producing. In particular, individual actors may benefits from integrate communication and promotion activities performed by the TBE. It represents a local brand that propose a diversified tourism offer, contributing to local tourism development and to increase the local competitiveness respect to other geographical areas. This is the case of a Touristic Associations that aim to promote tourism activities in a specific territory and offer to tourism operator a "showcase" in order to promote their own services. While a TBE promotes a common brand, a slogan, a symbol, etc., individual operators are responsible for the accuracy and the correctness of the information provided about offered services.

At Networking level, it is possible to identify a set of ICT solutions representing a valid support for promoting a tourist destination:

- Inspiration Portals: websites promoting the sharing of multimedia content among users by allowing them to get a preview of territories, places, cultures and type of vacation that will inspire potential tourists [26].

- Tourism Services Comparators: web portals that allow travelers to compare tourism services offered by different providers. Travelers have the possibility to compare services providers and chose the offer that best suits their needs [27]. 
- Tourism Social Networks: collection of individuals who share information, opinions and contents about tourism in an online setting over the internet [14].

- Mobile and Immersive Technologies: technologies that harness the potential of mobile devices to provide information, geolocation, and augmented reality services; information about the surrounding real world becomes interactive and digitally manipulable [28]. Mobile services support users with additional information such as maps, points of interest, tourist guides that overlaid the real world. Tourists interact with the surrounding reality and get information on areas of interest typical of tourist services (hotels, restaurants, etc.) and public utilities services (public transport networks, events, etc..,).

From a functional viewpoint, process automation is low being related to supporting horizontal communication with the aim of developing teamwork, share information and promoting activities' coordination within and among organizations. From a technological point of view, automation technologies are intended to supporting communication technologies between tourism operators and tourists.

Level 2 - Coordination. In addition to communication and information exchange, more organizational commitment is evident at this level. Coordination involves aligning/altering activities so that more efficient results are achieved; nevertheless each networks member might have a different goal and use its own resources. In order to expand its own tourism offer and capture new customers, a tourism operator can tighten symbiotic relationship with other tourism operators that complement each other or have reciprocal products. This is the case of an operator which originates a TEE that "extend" business services, proposing to customers complementary tourism services provided by other tourism operators.

At the coordination level, ICTs are intended to support automation of interorganizational business process. In addition to the tools typical of the networking level, at this level technologies need to support tourist to take advantage of integrated offerings. Examples of such technologies are the Destination Management Systems $(D M S s)$, i.e. systems that gather into a single portal a variety of tourism services provided by heterogeneous tourism operators and related to a specific geographical area. DMS attempt to utilize a customer centric approach in order to manage and market the destination as a holistic entity, typically providing strong destination related information, real-time reservations, destination management tools and paying particular attention to supporting small and independent tourism suppliers [29].

Level 3 - Cooperation. In addition to level 2, it involves knowledge and resources' sharing for achieving compatible goals of TBE. In this case the aggregated value is the result of the addition of individual "components" of value generated by the various participants in a quasi-independent manner. A common plan exists which in most cases is not defined jointly but rather designed by a single entity. Participants' goals are compatible in the sense that their results can be added or composed in a value chain leading to the end-product or service. Trust plays a key role in the willingness of network members to cooperate in tourism services provision. The risk of opportunism is crucial at this level and it is mainly based on partners' behavior manifested during group's interaction. A partner needs to signify its trustworthiness through the way it be haves in the alliance. This is the case of a TBE that allows tourist to compose a customized tourism package (whether by means of an automated 
tourism packaging system or supported by a travel agency operator) combining and organizing services provided by multiple tourism actors members of the TBE. The composition of a such tourism package indirectly determine the creation of a TVO among the providers of each service in the package. In the TVO, each tourism services provider is responsible for the correct provision of its part of the service.

At this level it is desirable to use web and mobile based systems which enable consumers to build their own tourism package made of flights, accommodation, and other tourism services instead of purchasing a predefined package from a catalogue. This kind of technologies are known as Tourism Dynamic Packaging Systems, TDPS, whose characteristics are: full automation through online applications; real-time update of travel product information; single price for an entire tourism package. From a process automation point of view, distributed business processes management tools are required in order to allow integration and communication processes between individual information systems adopted by tourism each operator [30].

Level 4 - Collaboration. At this level, all entities share information, knowledge, resources and responsibilities to jointly plan, implement and evaluate a program of activities to achieve a common goal. It implies sharing risks, resources, responsibilities, and rewards. Tourist operators committed in collective decision process have common values and visions. The TVO becomes a self-organizing system with global properties that cannot be predicted from the properties of the economic actors who are directly involved in it. This is the case of a TBE that allows the composition of a customized tourism package in a seamless and transparent way to the customer. Partners of the resulting TVO have joint identity, goals and responsibility; the TBE constitutes the unique interface for the customer and it's responsible for the correct provision of the tourism package.

At this level the inter-organization process planning and management regards many operative and supporting processes which are managed in a common way. The CNOs can be supported by a form of Enterprise Resource Planning technologies for tourism networked organizations also known as a Cloud-Based Business Network that connects and coordinates the ERP of each networked tourism operator on a common platform. "Business networks supplement ERP systems, rather than replacing them. The ERP system remains the system of record and the guardian of the internal processes of the enterprise, while the business network provides the system of process, the platform for working with trading partners to meet customer needs profitably and expeditiously" [31].

\section{Conclusions}

The importance of setting a TBE is related both to the necessity to answer to the request of personalized tourism offer, in line with the new demand trends, and to the possibility to give sustainable development to local tourism players in the effort to overcome limits of touristic organization's size and reach economy of scale and competitiveness in contrast to big players. The availability of organizational models and ICT supporting solutions make possible the operationalization of the collaboration concept in the tourism sector and the setting up of CNOs in a TBE at different level of collaboration, in line with the territorial development strategies and 
tourism operators' propensity to risk taking. In this paper we proposed a characterization of the organizational forms of collaborative organizations proper of the tourism sector and discussed the possible levels of collaboration that can be observed in those forms. Further studies are undergoing in order to provide a mechanism to identify and assemble competencies in a TBE in order to determine the source and type of competencies needed to efficiently and timely catch opportunities and to individuate the best TBE partners to involve to carry out a specific business.

\section{References}

1. Wan Lee, J., Brahmasrene, T.: Investigating the influence of tourism on economic growth and carbon emissions: Evidence from panel analysis of the European Union. Tourism Management 38, 69-76 (2013)

2. World Travel \& Tourism Council. Travel \& Tourism Economic Impact (2009)

3. Polo Peña, A.I., Frías Jamilena, D.M., Rodríguez Molina, M.A.: Impact of Customer Orientation and ICT Use on the Perceived Performance of Rural Tourism Enterprises. Journal of Travel \& Tourism Marketing 30(3), 272-289 (2013)

4. Stamboulis, Y., Skayannis, P.: Innovation strategies and technology for experience-based tourism. Tourism Management 24, 35-43 (2003)

5. Mills, J., Law, R.: Handbook of consumer behavior, tourism and the Internet. Haworth Hospitality Press, New York (2004)

6. Erkus-Otzurk, , H., Eraydın, A.: Environmental governance for sustainable tourism development: Collaborative networks and organisation building in the Antalya tourism region. Tourism Management 31, 113-124 (2010)

7. Plummer, R., Telfer, D., Hashimoto, A.: A Study of Collaboration within the Tourism Industry. Current Issues in Tourism 9(3), 191-205 (2006)

8. Jamal, T.B., Getz, D.: Collaboration theory and community tourism planning. Annals of Tourism Research 22(1), 186-204 (1995)

9. Selin, S., Myers, N.A.: Tourism marketing alliances: member satisfaction and effectiveness attributes. Journal of Travel and Tourism Marketing 7(3), 79-93 (1998)

10. Volpentesta, A.P., Ammirato, S., Sofo, F.: Collaborative design learning and thinking style awareness. The International Journal of Engineering Education 28(4), 948-958 (2012)

11. Volpentesta, A.P., Ammirato, S., Sofo, F.: Thinking style diversity and collaborative design learning. In: Camarinha-Matos, L.M., Paraskakis, I., Afsarmanesh, H. (eds.) PRO-VE 2009. IFIP AICT, vol. 307, pp. 785-796. Springer, Heidelberg (2009)

12. Sofo, F., Ammirato, S.: Establishing a Learning Culture: the Importance of Relationships within an Organization. In: Lytras, M.D., Ruan, D., Tennyson, R.D., Ordonez De Pablos, P., García Peñalvo, F.J., Rusu, L. (eds.) WSKS 2011. CCIS, vol. 278, pp. 271-277. Springer, Heidelberg (2013)

13. Sofo, F., Berzins, M., Colapinto, C., Ammirato, S.: North, south, least, best: Geographical location and the thinking styles of Italian university students. Australian Journal of Adult Learning 49(2), 269-291 (2009)

14. Mihajlović, I.: The Impact of Information and Communication Technology (ICT) as a Key Factor of Tourism Development on the Role of Croatian Travel Agencies. International Journal of Business and Social Science 3(24), 151-159 (2012) 
15. Volpentesta, A.P., Ammirato, S.: Networking agrifood SMEs and consumer groups in local agribusiness. In: 9th IFIP WG 5.5 Working Conference on Virtual Enterprises, PRO-VE 2008: Pervasive Collaborative Networks, Poznan, Poland. International Federation for Information Processing, vol. 283, pp. 33-40 (2008)

16. O'Connor, P., Frew, A.J.: An evaluation methodology for hotel electronic channels of distribution. International Journal of Hospitality Management 23(2), 179-199 (2004)

17. Volpentesta, A.P., Felicetti, A.M.: Identifying opinion leaders in time-dependent commercial social networks. In: Camarinha-Matos, L.M., Xu, L., Afsarmanesh, H. (eds.) PRO-VE 2012. IFIP AICT, vol. 380, pp. 571-581. Springer, Heidelberg (2012)

18. Ammirato, S., Felicetti, A.M.: The potential of agritourism in revitalizing rural communities: Some empirical results. In: Camarinha-Matos, L.M., Scherer, R.J. (eds.) PRO-VE 2013. IFIP AICT, vol. 408, pp. 489-497. Springer, Heidelberg (2013)

19. Wanga, Y., Fesenmaier, D.R.: Collaborative destination marketing: A case study of Elkhart county. Indiana, Tourism Management 28, 863-875 (2007)

20. Volpentesta, A. P., Ammirato, S., Alternative Agrifood Networks in a regional area: a case study. The International Journal of Computer Integrated Manufacturing, special issue on Collaborative Networks as Modern Industrial Organizations: Real Case Studies 26(1-2), 55-66, (2013),

21. Volpentesta, A.P., Ammirato, S.: Networking agrifood SMEs and consumer groups in local agribusiness. In: 9th IFIP WG 5.5 Working Conference on Virtual Enterprises, PRO-VE 2008: Pervasive Collaborative Networks, Poznan, Poland. IFIP International Federation for Information Processing, vol. 283, pp. 33-40 (2008)

22. Loss, L., Crave, S.: Tourism Breeding Environment: Business Processes Applied to Collaborative Networks in Tourism and Entertainment Sector. In: Camarinha-Matos, L.M., Pereira-Klen, A., Afsarmanesh, H. (eds.) PRO-VE 2011. IFIP AICT, vol. 362, pp. 197-204. Springer, Heidelberg (2011)

23. Volpentesta, A.P., Ammirato, S.: Enabling Virtual Organizations in a Technological District. In: Camarinha-Matos, L.M., Afsarmanesh, H., Novais, P., Analide, C. (eds.) Establishing the Foundation of Collaborative Networks. IFIP, vol. 243, pp. 103-110. Springer, Boston (2007)

24. Corvello, V.: An empirical study of individual factors affecting the usefulness of internetbased platforms for open innovation in broadcast search processes. International Journal of Digital Content Technology and its Applications 7(4), 821-829 (2013)

25. Camarinha-Matos, L., Asarmanesh, H.: Collaborative Networks: Value creation in a knowledge society. In: Wang, K., et al. (eds.) Knowledge Enterprise: Intelligent Strategies in Product Design, Manufacturing and Management, pp. 26-40. Springer, Boston (2006)

26. Not, E., Venturini, A.: Supporting Users in Organizing their Vacation Before, During, and After the Travel. In: Gretzel, U., et al. (eds.) e-Review of Tourism Research (2010)

27. Zanker, M., Fuchs, M., Höpken, W., Tuta, M.: Evaluating Recommender Systems in Tourism. Information and Communication Technologies in Tourism, 24-34 (2008)

28. Emmanouilidis, C., Koutsiamanis, R., Tasidou, A.: Mobile guides: Taxonomy of architectures, context awareness, technologies and applications. Journal of Network and Computer Applications 36(1), 103-125 (2013)

29. Akoumianakis, D.: Ambient affiliates in virtual cross-organizational tourism alliances: A case study of collaborative product development. Computers in Human Behavior (2013)

30. Zach, F., Gretzel, U., Fesenmaier, D.L.: Tourist Activated Networks: Implications for Dynamic Packaging Systems in Tourism Information and Communication Technologies in Tourism, pp. 198-208 (2008)

31. E2OPEN, White Paper: ERP and the Business Network, (2013) 